\title{
FEATURE \\ A strategic plan for future USDA Agricultural Research Service erosion research and model development
}

Mark A. Weltz, Chi-Hua Huang, Beth A. Newingham, John Tatarko, Sayjro K. Nouwakpo, and Teferi Tsegaye

$\mathbf{S}$ oil erosion is a natural process, and the erosion potential of a site is the result of complex interactions among soil, vegetation, topographic position, land use and management, and climate. Soil erosion occurs when aeolian and hydrologic processes exceed a soil's inherent resistance to these forces (figures 1 and 2). Soil erosion was recognized as a significant problem at both local and national scales in the United States in the 1920 s; by 1935 soil erosion was considered a national disaster, covering over one-half of the country (Sampson and Weyl 1918; Weaver 1935), and is still a concern with $21 \%$ of the western United States degraded and vulnerable to accelerated soil erosion (Herrick et al. 2010; Weltz et al. 2014a; Duniway et al. 2019). In 1995, it was estimated that $4 \times 10^{9} \mathrm{t}$ $\left(4.4 \times 10^{9} \mathrm{tn}\right)$ of soil was lost from US cropland (Pimentel et al. 1995). The most vulnerable areas for soil movement and thus erosion occur where annual precipitation is 100 to $400 \mathrm{~mm} \mathrm{y}^{-1}$ (4 to 16 in $\mathrm{yr}^{-1}$ ), which limits soil moisture available to sustain plant growth. Anthropogenicdriven dust emissions have dramatically increased across the globe (Webb and Pierre 2018) and in the United States (Neff et al. 2008) over last several decades. On-site and off-site costs associated with wind erosion exceeds US $\$ 8$ billion $\mathrm{y}^{-1}$ (figure 2) (Huszar and Piper 1986; USDA 1993). The combined off-site and on-site costs of erosion from agriculture in the United States is estimated to be about US $\$ 44$ billion $\mathrm{y}^{-1}$, or about US $\$ 100$ $\mathrm{ha}^{-1}$ (US $\left.\$ 40 \mathrm{ac}^{-1}\right)$ of cropland and pasture (Pimentel et al. 1995), and US\$44.5 billion in the European Union (Montanarella 2007). Cropland and livestock production contribute US $\$ 132.8$ billion or $1 \%$ of the US gross domestic product. Erosion increases production costs by $\sim 25 \%$ each year.

The USDA has a long history of conducting basic research in soil erosion and developing erosion assessment tools

\section{Figure 1}

Water erosion processes on rangelands: (a) convective thundershower; (b) raindrop splash erosion; (c) sheetflow erosion; (d) concentrated flow erosion; (e) channel erosion during a flash flow; and (f) gully erosion.

(a)

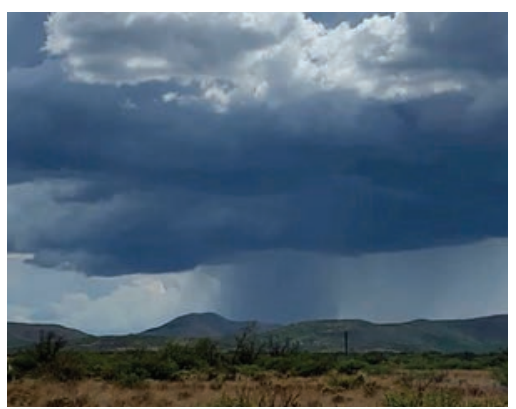

(c)

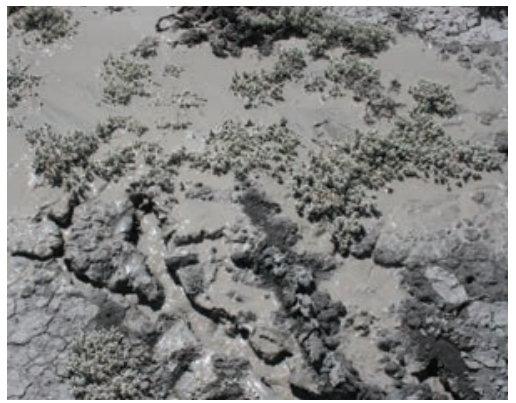

(e)

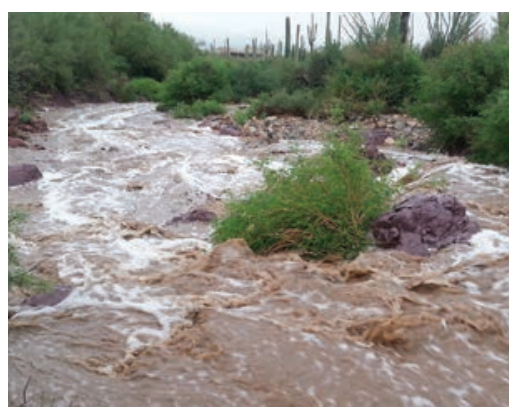

(b)

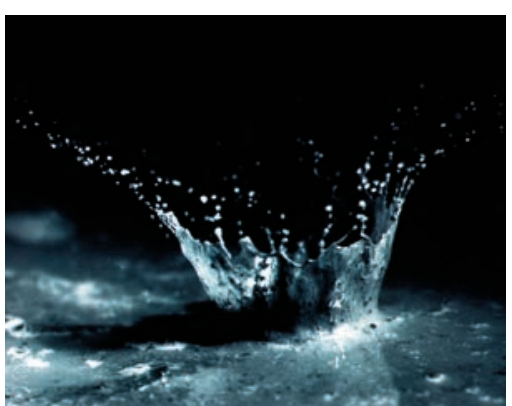

(d)

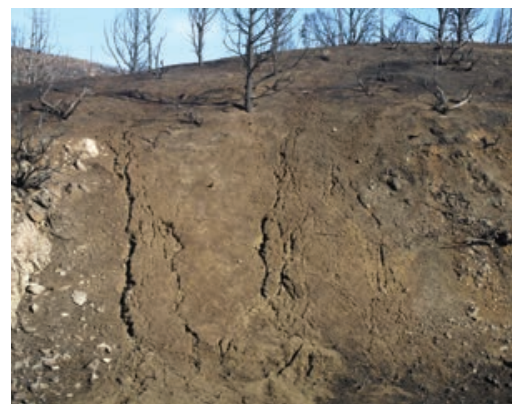

(f)

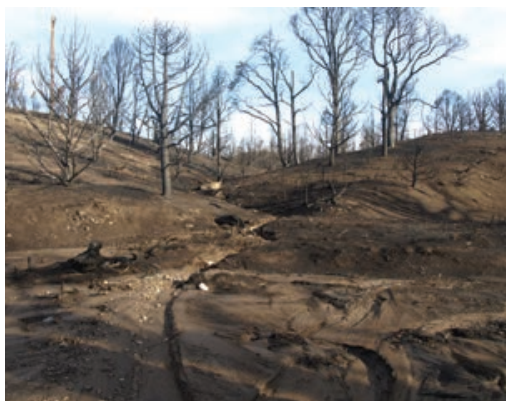

used for conservation planning and risk assessment. However, research efforts and model development have historically been segregated, and researchers in these two fields have therefore developed separate soil erosion assessment tools. The basis of mathematical equations used to estimate water erosion can be traced to the work of Cook (1937), who identified three major variables: (1) the susceptibility of soil to erosion, (2) the potential erosivity of rainfall and runoff, and (3) the protection

Received August 5, 2020. 


\section{Figure 2}

Wind erosion impacts: (a) Dustbowl devastation; (b) postfire erosion on rangeland; (c) cropland erosion; (d) off-site deposition; (e) traffic visibility reduction; and (f) air quality impact on a global scale.

(a)

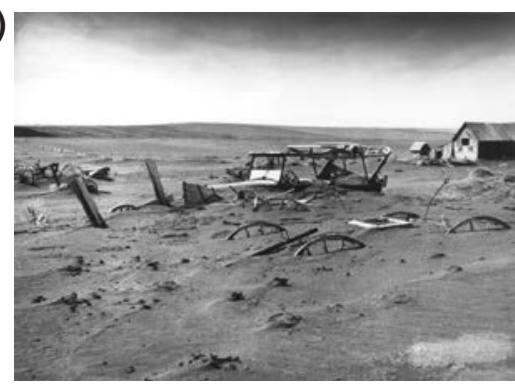

(c)

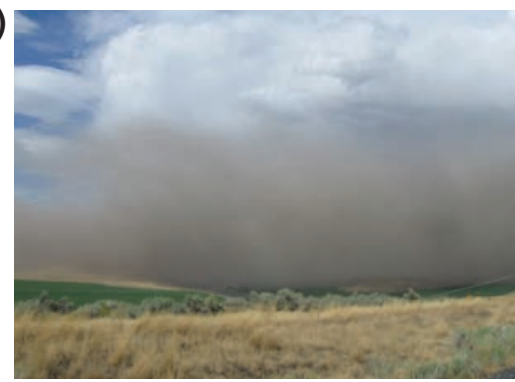

(e)

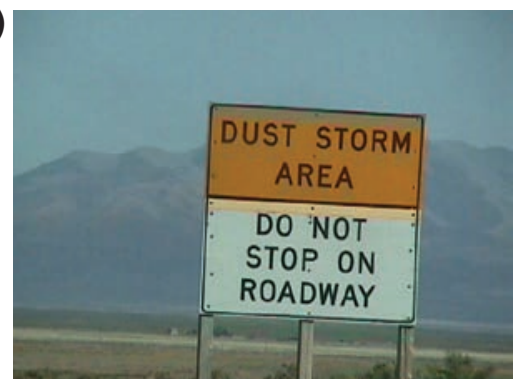

offered by vegetation. Smith and Whitt (1948) proposed the "rational" equation to estimate soil erosion that incorporated the average annual soil loss for a specific site and crop rotation on a 90-foot slope with a 3\% grade. They added nondimensional multipliers to adjust the plot soil loss for differences in slope, length, soil group, and supporting practices. During the 1960s and 1970s, the rainfall factor was added to form the empirically based Universal Soil Loss Equation (USLE) (Wischmeier and Smith 1965; Wischmeier and Smith 1978). During this same time period, a different group of scientists developed the empirical Wind Erosion Equation (WEQ) (Woodruff and Siddoway 1965). The WEQ was solved using a series of charts and lookup tables using similar factors of climate, erodibility, surface roughness, field length, and vegetative cover. The WEQ (b)

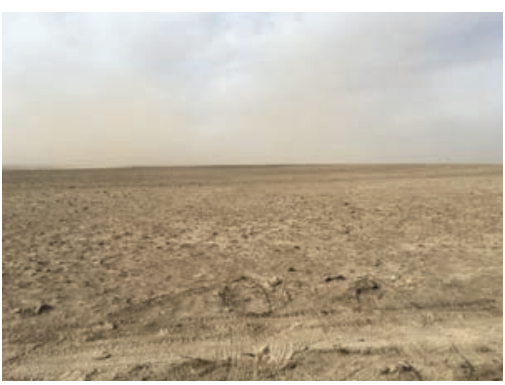

(d)

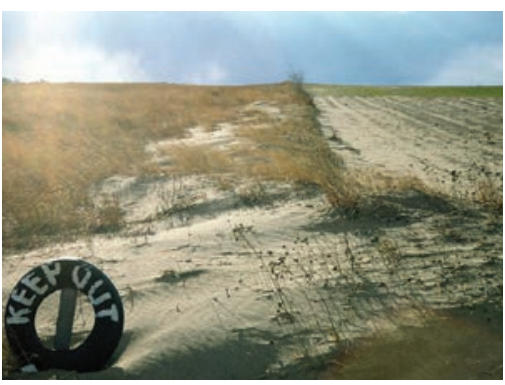

(f)

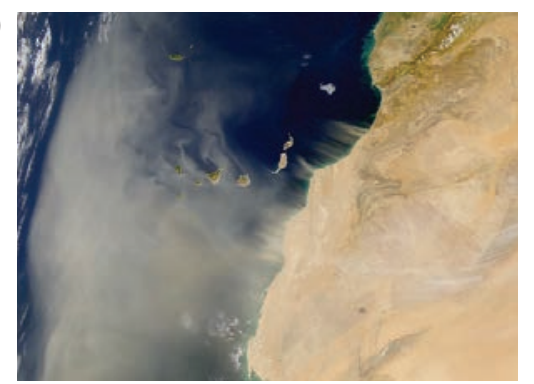

and USLE have many limitations that prevented their universal application on crop- and rangelands.

In response to these limitations, the USDA Agricultural Research Service (ARS) initiated the development of improved prediction tools to address water and wind erosion. Revised Universal Soil Loss Equation (RUSLE) (Renard et al. 1997) was released for public use in 1992 with the major advancement of using subfactor relationships to compute cropping C-factors for water erosion from basic cover crop management systems. Development of RUSLE2 (Version 2) began in 1993 and was implemented in USDA Natural Resource Conservation Service (NRCS) field offices starting in 2002. In the 1990s, the transition from empirical models to process-based models was initiated. The Water Erosion
Prediction Project (WEPP) model was developed to estimate soil loss at hillslope and small watershed scales (Flanagan and Nearing 1995).

The Wind Erosion Prediction System (WEPS) model simulates interactions between wind, management operations, soil and water dynamics, plant growth, residue decomposition, and soil erodibility to predict cropland soil loss at the field scale (Tatarko et al. 2019). ARS released the Rangeland Hydrology and Erosion Model (RHEM) in 2006 and subsequently enhanced the tool with an updated version in 2017 (Hernandez et al. 2017). The RHEM can capture the influence of soils; plant growth/life forms; disturbances, such as fire, grazing, and climate change; and rangeland management practices on important hydrological and erosion processes (Zhang et al. 2012; Weltz et al. 2014b; Al-Hamdan et al. 2017; Nouwakpo et al. 2017).

In September of 2019, the ARS and stakeholders (NRCS, US Forest Service) met to discuss the future needs in erosion research and modeling. Four goals were defined along with associated products and deliverables. The need for future scientists and funding to achieve these goals was also outlined.

\section{GOAL 1: ADVANCE WIND AND WATER EROSION SCIENCE}

\section{Continue to Build a Basic Science} Framework for Next-Generation Erosion Models that Incorporate Dynamic Soil Erodibility, Sediment Transport, and Transient Surface Condition at the Landscape Scale. Current modeling techniques for wind and water erosion processes were formulated more than 30 years ago. At that time, some of the basic concepts in sediment detachment, transport, and deposition were emerging, resulting in assumptions and simplifications of these physical processes. The supporting modules for erosion calculations, such as infiltration, water balance, and plant growth, were simplified because of computational constraints. However, surface topography, above- and belowground biomass, landscape complexity, and subsurface hydrology may affect the erosive power of wind and water and potential soil erodibil- 
ity. These complex surface and subsurface dynamics need to be accounted for in new erosion prediction technologies.

The downstream impact of eroded sediments from wind and water is also a critical issue as large quantities of eroded materials are deposited in channels and reservoirs. Reservoirs fill with sediment, which reduces flood water storage and increases the likelihood for an auxiliary spillway release and/or overtopping of the embankment. Processes, such as sediment transport and deposition, channel erosion, and spillway and dam failure, need to be an integral part of the next-generation erosion assessment system. Challenges also exist in moving from a field scale to address wind erosion at a watershed or landscape scale where soil is deposited downwind. Wind erosion on rangelands needs to be better understood to improve erosion assessments and account for landscape complexity. Current methods to predict sediment detachment and transport generally cannot be extrapolated to new scenarios and across multiple spatial scales without new understanding of erosion processes.

New Interactive Erosion Science for Landscapes. Current water and wind erosion prediction technologies are designed to simulate processes at the field scale for conservation planning. However, erosion and deposition occur across field boundaries with differing land use and land cover. There is a need to use equations based on the same physical principles for both water and wind detachment, transport, and deposition processes across the four dimensions of length, width, depth, and time, which account for effects of topography, subsurface hydrology, vegetation distribution, and canopy and surface roughness. Newer experimental approaches are needed to examine sediment detachment, deposition, and loads with finer spatial resolution to address sheet and channel erosion. Water erosion research also needs to include components, such as incipient channel erosion and development of ephemeral gully, edgeof-field classical gully, channel erosion, irrigation-induced erosion, wave-action along water bodies and embankments, and earth dam and spillway failures. Similarly, wind erosion research needs to account for topography, structural diversity, and the selective removal of finer particles and organic matter. Both wind and water erosion processes transport and deposit sediments on the landscape, which needs to be quantified and incorporated into the next generation of erosion assessment tools.

Assessing Conservation Effects on Environmental Quality. There remains a large disconnect between field-scale management and the adoption of conservation practices in sediment source areas and its impacts on off-site environmental quality. Little is known about the interactions of wind and water erosion processes with nutrient cycling (e.g., carbon [C], nitrogen $[\mathrm{N}]$, and phosphorus $[\mathrm{P}])$. When sediments are transported and deposited on the landscape, they can either be a source or sink of $\mathrm{C}$ and other nutrients. Information is needed on how erosion processes affect nutrient budgets and their interactions across agroecological systems, as well as the effects on production system resilience to climate stressors. Irrigation is increasingly used across the globe to enhance agricultural productivity, but insufficient knowledge exists to predict irrigationinduced erosion with reasonable accuracy. In irrigated agricultural systems, erosion is caused by a combination of natural precipitation, wind events, and irrigation. Additional experimental and modeling research efforts are needed to better understand how the choice of irrigation practices (e.g., pressurized versus gravity systems) interact with other management actions, field conditions, and environmental factors to affect soil erosion. Future soil erosion models need to also seamlessly incorporate new irrigation technologies to better evaluate the effect of irrigation innovations on environmental quality.

Soil Loss Tolerance. Soil loss tolerance ( $\mathrm{T})$ is an estimate of the maximum rate of soil loss that can occur on a specific soil type and still sustain a high level of productivity. However, soil loss tolerance does not address the full range of ecosystem services provided by soils. Attempts to extend the concept of soil loss tolerance from cropland to rangelands are questionable because of the fragility of rangeland ecosystems, the irreversibility of soil loss, and large errors associated with measuring soil loss. There is a need to reevaluate the T-value concept for both on- and off-site effects and incorporate the concept of risk assessment as a component of soil health for all land uses.

Representing Short- and Long-Term Soil Erodibility Dynamics through Expanding Erosion Data Network with Modern Technology. Validating processbased models requires developing the ability to measure sediment movement and deposition on the landscape. This will involve using tracers and new technologies that quickly and precisely measure sediment transport and/or changes in soil surface microtopography, major erosional features, and deposition areas. Physically based erosion models represent soil erodibility as a function of basic soil properties and do not account for dynamic soil surface conditions, such as physical, chemical, and biological soil crusting, and loose erodible materials from prior wind and water erosion events or disturbances. Long-term cropping and management can change soil organic matter content, aggregate stability, and baseline soil erodibility. These short- and long-term changes in soil erodibility and erosion processes will be captured and data integrated within the soil health research being undertaken in the ARS's Long-Term Agroecosystem Research (LTAR) sites that monitor wind and water processes through space and time on the same site to provide the essential data needed to test, calibrate, and validate erosion models (figure 3 ).

Products and Deliverables. The following products and deliverables are needed:

- Spatially and temporally scalable erosion science that accounts for sediment sources and sinks that can be developed into tools for conservation planning, as well as environmental quality and risk assessments.

- A network of LTAR sites that monitor aeolian and water processes through space and time with state-of-the-art measurement technologies to generate common databases suitable for use in artificial intelligence and machine learning and to develop the next generation of erosion and sedimentation tools.

- Fully quantified short- and long-term effects of wind and water erosion on $\mathrm{C}$ 


\section{Figure 3}

Current distribution of Long-Term Agroecosystem Research (LTAR) sites. New LTAR sites may be established in areas circled in red to address areas not currently measuring aeolian and fluvial fluxes, spatial distribution of soil loss and deposition, and sediment yield.

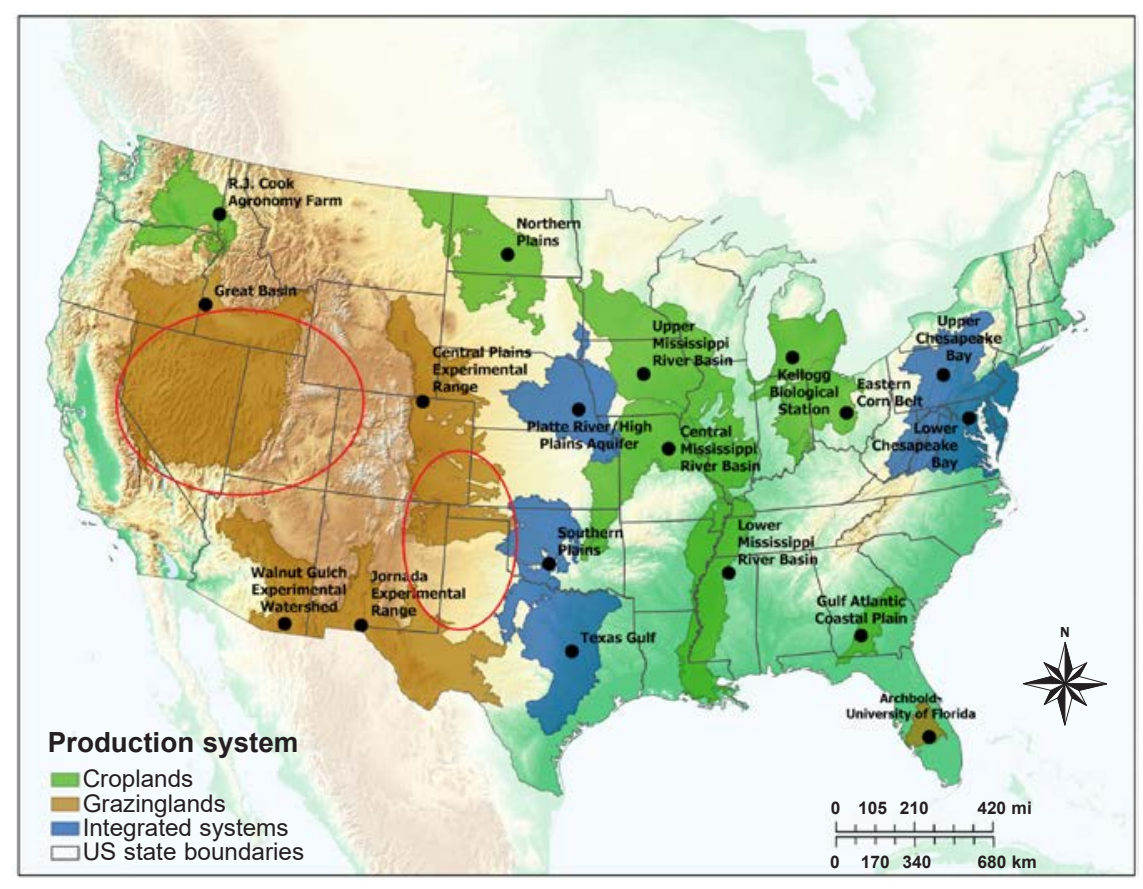

and other nutrient cycling; soil, water, and air quality; ecosystem services; and landscape dynamics.

\section{GOAL 2: IMPROVE THE CLIMATE MODEL FOR EROSION PREDICTION}

Incorporate Near Real-Time and Modern Data Inputs, Enhance Climate Representation, and Add Capabilities for Forecasting Climate Variability and Assessing Climate Change Scenarios. The climate drivers used in current erosion prediction technologies do not sufficiently represent future climate parameters. An improved climate engine using artificial intelligence and machine learning would incorporate traditionally instrumented climate networks and various modeled gridded products to produce consistent climate forcing at required spatial and temporal scales. This climate engine could be used to forecast past, present, and future climate scenarios and corresponding uncertainties for climate variability and climate change. tions, and time periods. consistent, useable outputs for wind and water erosion predictions.

Quantifying and Separating LongTerm Climate Variability, Climate Change Effects, and Uncertainty. Climate cycles or oscillations can influence climate data variability. For instance, the climate data used to estimate USLE erosivity were collected during the strong positive phase of the Atlantic Multidecadal Oscillation. Therefore, future climate engines must account for large area teleconnections to quantify trends at subdaily scales derived from long-term precipitation observations at ARS experimental watersheds.

Products and Deliverables. The following products and deliverables are desired:

- A climate data library with access to both historic and current climate datasets and inputs that can be used for erosion prediction and environmental assessment.

- A software system used to assimilate and synthesize climate datasets, in order to derive climate-related parameters for erosion predictions at different spatial and temporal scales.

\section{GOAL 3: QUANTIFY FACTORS AFFECTING EROSION}

Climate Databases. Climate databases have undergone extensive changes throughout the last century, especially those related to precipitation. These changes complicate the already demanding task of preparing climate inputs for erosion models. New developments must maintain consistency across these databases despite changes in measuring technologies, methods, loca-

Integrating and Validating New Climate Databases. As measurement techniques and datasets are becoming more advanced and at a much higher resolution, the improved climate driver must incorporate state-of-the-science technologies to facilitate erosion prediction. With the improvements in remote sensing and ground-based weather radars, gridded climate inputs are becoming more available over time. Therefore, a future climate engine should handle data from both gaged networks and gridded products, including trends and uncertainties in spatial and temporal resolutions, and produce
Improve the Understanding of the Impact of Natural and Anthropogenic Factors on Erosion, such as Wildfire, Winter Processes, Cropping, Management, and Conservation Practices. Natural and anthropogenic factors affect erosion at a wide range of spatial and temporal scales. For example, tillage-induced microtopography or surface roughness at the clod scale can change within a single rain- or windstorm, but the oriented roughness from tillage implements (e.g., wheel tracks) may last throughout the entire growing season or decades on rangelands. These random and oriented roughness parameters affect the erosive power of the wind and rain and soil erodibility. Canopy effects in row crops follow an annual growth cycle, but for rangelands the vegetation may be eliminated after a wildfire event and it will take years for plants to reestablish and restore the canopy structure. Within the past year, severe wildfires in the US West and spring flooding in the Midwest have caused significant erosion events. Although some of these natural and management effects on erosion 
have been incorporated into current models, significantly more information is needed to improve soil erosion assessments.

Representing Temporal Effects of Fire and Fire Management. Wildfire remains one of the most prominent disturbances impacting rangeland and forested landscapes with amplified runoff and erosion postfire posing substantial hazards to resources, property, infrastructure, and human life. Although current rangeland models, i.e., RHEM and Automated Geospatial Watershed Assessment (AGWA), are capable in predicting postfire runoff and erosion risks, questions remain regarding how to parameterize these models across the vast domain of rangelands and woodlands. Additionally, although millions of acres burn each year in drylands where wind erosion is of concern, postfire wind erosion research is in its infancy. More information is needed about when, where, and how long wind erosion events will occur after wildfire, including research on wind erosion processes and implications for ecosystem services and forage productivity.

Cold-Season Processes. Erosion from cold-season hydrologic processes on croplands, rangelands, and forested regions remains understudied. For snow-dominated areas, the highest erosion rates are commonly the result of cold-season processes, such as rain-on-snow, rainon-frozen soils, and snowmelt runoff. Repeated freezing and thawing break down aggregates, resulting in friable surfaces prone to wind and water erosion, particularly in the postfire environment. Flooding in the Magic Valley of Idaho (February of 2017) and western Iowa (March of 2019) illustrate this vulnerability to extreme winter conditions.

Water Management Effects. Surface and subsurface water management practices affect water routing and distribution and thus the overall water balance on the landscape. On irrigated land, the mode of application and quality of the irrigation water are significantly different from natural rain. Drainage installations alter how water is moved and sediments transported from fields to channels. A proper accounting of surface and subsurface water and its management effects are essential in new 3D landscape erosion modeling systems.

Plant-Soil Interactions and Conservation Effects in Rangeland Ecosystems. Disturbances in western rangelands have substantially increased via wildfire, plant invasions, energy development, livestock grazing, off-road recreation, and extended drought. The direct impact of these disturbances on erosion processes and consequences for ecosystem processes (e.g., plant establishment and survival, spatial distribution, productivity, nutrient cycling, etc.) is poorly known. Further research is needed on the effects of disturbance and restoration on potential plant-soil feedbacks involving physical, chemical, and biological soil properties, as well as associated effects on plant communities. In addition, little quantitative information is available on how rangeland conservation practices (e.g., prescribed grazing) and disturbances (fire, off-road vehicles, and oil and gas development) affect wind erosion and dust emissions. This information is needed to enhance the selection of management practices and restoration for eroding and degraded rangelands.

Improved Plant Growth Representation. Current modeling approaches are limited in their ability to adequately simulate the growth and development of all types of plant species and growing conditions, i.e., cropland, rangeland, forests, orchards, vineyards, irrigated lands, and urban areas. Improvements are needed, especially for groups of multiple different plant types growing together (e.g., intercropping, rangeland communities, etc.) in continuous model simulations.

Products and Deliverables. The following are needed:

- Databases and models to quantify short- and long-term effects of management and disturbances on erosion and restoration potential.

- Ecological Site Descriptions (ESD) with hydrologic and erosion interactions for the various states described within rangeland ESDs.

- Effects of cold-season processes and water management practices on wind and water erosion that are quantified and incorporated into the new erosion prediction system.

- Improved water balance and plant growth submodels.

\section{GOAL 4: DEVELOP AN INTEGRATED WIND AND WATER EROSION PREDICTION SYSTEM}

A Transparent and Sustainable Software System with Common Interface and Databases for Erosion Assessment across Spatial and Temporal Scales that Serves User Needs. Wind and water erosion research, with their respective science models, associated interfaces, climate generators, and databases, were historically developed independently. This independent development approach has led to similar but not identical simulation and reporting. These differences cause confusion in the user community about which value is "correct." To address this, the new integrated erosion tool will use common components of subprocesses to support the erosion model. Such a model would share the exact same core science code and inputs and guarantee consistent, identical, intermediate results, which are then used as inputs in both the wind and water erosion scenarios.

Combining Wind and Water Erosion Processes with Common Routines. Combining wind and water erosion models across different land uses is a crucial need for NRCS and other users. The new modeling system will have common databases with identical support modules for climate, hydrology, water balance, plant growth, residue decomposition, soil, and management effects. The new system will also account for the interaction of wind and water erosion. For example, wind erosion deposits loose sediments in fields and streams that subsequently are eroded and transported by rain and runoff water. Similarly, unvegetated alluvium acts as a source area for aeolian entrainment.

Temporal and Spatial Flexibility. Current wind and water erosion models for croplands operate at daily time steps that may not be the best approach for all cases, such as rangeland applications where the day-to-day changes may not be significant enough to warrant a computer-intensive daily time step modeling approach. Additionally, these models were 
developed for a specific spatial scale. The new erosion system will have dynamic flexibility in adjusting its temporal and spatial resolution and range of coverage depending on the specific use of the model. The new erosion modeling system will simulate variability across temporal (from single storms to multiple events) and spatial scales (from local sites to larger regions) that encompass different soil, land management, 2D/3D topographic, and transient surface conditions and have the capacity for accessing and processing readily available datasets from remote sensing and other sources (i.e., burn severity map, ecological sites, soil properties, climate, and topography).

Modeling Components Easily Integrated into Other Models. ARS hydrology and water quality models have incorporated different erosion technologies from empirical USLE-type to process-based. The new erosion system will be designed such that the erosion estimates can be incorporated into other modeling software. Similarly, supporting modules, such as water balance, plant growth, yield and biomass production, and residue decomposition, will have separate reporting capabilities for potential integration into other natural resource models. This includes documenting technical details so other modelers understand what the modules do and how the physical processes are implemented in the model code.

Model Complexity, Validation, and Uncertainty. Model complexity can come at the expense of understanding sources and magnitudes of uncertainties associated with the equations and the supporting data, as well as their impacts on model predictions. Model uncertainties and associated prediction confidence need to be communicated to and considered by stakeholders to support management decisions. Future erosion models will balance fidelity with parsimony so that models represent higher-order controls with quantifiable uncertainties and ranges of possible outcomes that can be clearly communicated to users. The new system will have methodology and subprograms to automate access of NRCS National Resources Inventory (NRI) data and the Bureau of Land Management Assessment, Inventory, and Monitoring (AIM) national datasets that will facilitate rapid national and regional assessments of the health of US agricultural lands.

Transformable Software Engineering for Delivery to Different Users. There will be a wide range of model users who require different user interfaces, from scientists doing detailed research and model development to policy makers wanting a quick dashboard summary of erosion estimates. In addition, some user communities will want to develop their own user interfaces or integrate the erosion software components into other models. There should be an application programming interface to allow the erosion science and associated software components to be used by other systems. The core computational engine and user interfaces will be built and maintained by a team of software engineers, such that the system can be upgraded seamlessly as the research progresses.

Products and Deliverables. The following products and deliverables are expected:

- An architectural design of the combined wind and water erosion system with updated science for all the processes and their interactions. The new system will be flexible to incorporate new erosion science and improved submodels as research progresses.

- Different user interfaces designed for different levels of complexity and specific user needs.

- A web application that is cloud-based and eliminates downloading and installing an application.

- A science code that can be integrated into other systems by providing an application programming interface or Web services.

- Automated access and data processing from national database sources, such as US Geological Survey, National Aeronautics and Space Administration, National Oceanic and Atmospheric Administration, and NRCS.

- A range in model estimates for risk analysis and uncertainty in model inputs.

- A model user support center that is dedicated to developing model user interfaces, facilitating the development and publication of model technical documents and user guidebooks, and hosting training on sponsored models.

\section{BUILDING FUTURE RESEARCH CAPACITY}

In developing the new USDA erosion research and prediction system, a transition plan has been created to ensure continuity of ongoing efforts with NRCS, especially during the first five years. This plan addresses staff availability and continuity of operations to replace staff when vacancies occur, as well as a mentoring strategy to ensure program integrity and the capacity to deliver products as scheduled. It is essential to preserve the current ARS knowledge on erosion simulation models, and there is an urgent need to pass on this knowledge and expertise to the next generation of engineers and scientists. Around $50 \%$ of ARS scientists conducting wind and water erosion research are eligible to retire as of 2020, and their current expertise in wind and water erosion modeling and data requirements must not be lost. New scientists are needed to address critical research needs in developing next-generation combined wind and water erosion models and participating as key members of model development teams using machine learning and artificial intelligence. The scientific personnel needed cross many disciplines, including climatology, hydrology, soil science, plant science, range management, ecology, cropping systems, geographic information systems, sensor network maintenance, computer engineering, and data assimilation. Additional personnel considerations include cooperating personnel from NRCS at ARS locations and sabbaticals to enable ARS scientists to work in teams and/or internationally to bring external ideas into ARS science.

A model user support center will be developed to lead the development of the standardized graphical user interfaces, answer questions, and track issues of concern by users of these erosion models. The model user support center will facilitate development of online training and tutorials to accelerate the speed of technology transfer.

The disciplines spanning wind and water erosion research across cropland and rangeland sectors will be dispersed geographically across research units. This will require forming core teams to col- 
laborate and review progress on common goals, host workshops, and provide training to key NRCS and ARS staff, who can then assist in regional and local training. New national research projects will be developed with shared objectives across different national programs within ARS, so that resources are optimized to address highest priority goals.

The USDA recognized the need to formulate a coordinated effort to develop the next generation soil erosion prediction system that contains the most current erosion science. To meet the current and growing challenges, USDA research capacity needs to be expanded across the nation to include an additional 26 scientist positions with an increase in base funds of US\$12 million. These new erosion prediction tools will (1) have interfaces that meet user needs and can incorporate data from multiple data sources; (2) implement software engineering standards, and (3) expand LTAR so that wind and water erosion processes in critical areas of the nation are monitored and national databases are developed and maintained.

\section{ACKNOWLEDGEMENTS}

The USDA Agricultural Research Service (ARS) Erosion Research and Model Development Strategic Plan was developed from a workshop held in September, 2019, Beltsville, Maryland. We want to thank the ARS National Program Leaders and scientists along with the scientific staff of US Forest Service, USDA Natural Resources Conservation Service, and university partners that provided us insights, gaps, and needs, and reviewed earlier drafts of the manuscript. Working together we can reduce soil erosion, enhance soil health, and ensure food and water security for future generations.

\section{REFERENCES}

Al-Hamdan, O.Z., F.B. Pierson, M.A. Nearing, C.J. Williams, M. Hernandez, J.Boll, S.K. Nouwakpo, M.A. Weltz, and K. Spaeth. 2017. Developing a parameterization approach for soil erodibility for the Rangeland Hydrology and Erosion Model (RHEM). Transactions American Society Agricultural Biological Engineers 60:85-94.

Cook, H.L. 1937. The nature and controlling variables of the water erosion process. Soil Science Society of America Journal 1:487-494.

Duniway, M.C., A.A. Pennigwerth, S.E. Fick, T.W. Nauman, J. Belnap, and N.N. Barger. 2019. Wind erosion and dust from US drylands: A review of causes, consequences, and solutions in a changing world. Ecosphere 10(3):e02650. https://doi. org/10.1002/ecs2.2650.

Flanagan, D., and M. Nearing. 1995. USDA-Water Erosion Prediction Project: Hillslope profile and watershed model documentation. West Lafayette, IN: USDA Agricultural Research Service National Soil Erosion Research Lab.

Hernandez, M., M.A. Nearing, O.Z. Al-Hamdan, F.B. Pierson, G. Armendariz, M.A. Weltz, K.E. Spaeth, C.J. Williams, S.K. Nouwakpo, and D.C. Goodrich. 2017. The Rangeland Hydrology and Erosion Model: A dynamic approach for predicting soil loss on rangelands. Water Resources Research 53:9368-9391.

Herrick, J.E., V.C. Lessard, K.E. Spaeth, P.L. Shaver, R.S. Dayton, D.A. Pyke, L. Jolley, and J.J. Goebel 2010. National ecosystem assessments supported by scientific and local knowledge. Frontiers in Ecology and the Environment 8:403-408.

Huszar, P.C., and S.L. Piper. 1986. Estimating the offsite costs of wind erosion in New Mexico. Journal of Soil and Water Conservation 41(6):414-416.

Montanarella, L. 2007. Trends in land degradation in Europe. In Climate and Land Degradation, eds. M.V.K. Sivakumar and N. Ndiang'ui, 83-104. New York: Springer.

Neff, J.C., A.P. Ballantyne, G.L. Farmer, N.M. Mahowald, J.L. Conroy, C.C. Landry, J.T. Overpeck, T.H. Painter, C.R. Lawrence, and R.L. Reynolds. 2008. Increasing eolian dust deposition in the western United States linked to human activity. Nature Geoscience 1:189-195, doi:10.1038/ngeo133.

Nouwakpo, S.K., M.A. Weltz, K.C. McGwire, C.J. Williams, O.Z. Al-Hamdan, and C.H. Green. 2017. Insight into sediment transport processes on saline rangeland hillslopes using threedimensional soil microtopography changes. Earth Surface Processes and Landforms 42:681-696, doi:10.1002/esp.4013.

Pimentel, D., C. Harvey, P. Resosudarmo, K. Sinclair, D. Kurz, M. McNair, S. Crist, L. Shpritz, L. Fitton, and R. Saffouri. 1995. Environmental and economic costs of soil erosion and conservation benefits. Science 267:1117-1123.

Renard, K.G., G.R. Foster, G.A. Weesies, D.K McCool, and D.C. Yoder. 1997. Predicting Soil Erosion by Water: A Guide to Conservation Planning with the Revised Universal Soil Loss Equation (RUSLE). Handbook \#703. Washington, DC: USDA.

Sampson, A.W., and L.H. Weyl. 1918. Range preservation and its relation to erosion control on western grazing lands. Bulletin No. 675 . Washington, DC: USDA.

Smith, D.D., and D.M. Whitt. 1948. Evaluating soil losses from field areas. Agricultural Engineering 29:394-398.

Tatarko, J., L. Wagner, and F. Fox. 2019. The Wind Erosion Prediction System and its use in conservation planning. In Bridging Among Disciplines by Synthesizing Soil and Plant Processes, Advances in Agricultural Systems Modeling eds. O. Wendroth, R.J. Lascano, and L. Ma, 71-101. Madison, WI: Agronomy Society of America, Crop Science Society of America, and Soil Science Society of America.

USDA. 1993. Wind Erosion Report, November 1992 - May 1993. Washington, DC: USDA Soil Conservation Service.

Weaver, J.E. 1935. Measurement of run-off and soil erosion by a single investigator. Ecology 16:1-12. Webb, N.P., and C. Pierre. 2018. Quantifying anthropogenic dust emissions. Earth's Future 6:286-295.

Weltz, M.A., L. Jolley, M. Hernandez, K. E. Spaeth, C. Rossi, C. Talbot, M. Nearing, J. Stone, D. Goodrich, F. Pierson, H. Wei, and C. Morris. 2014a. Estimating conservation needs for rangelands using National Inventory Assessments. American Society of Agricultural and Biological Engineers 57:1559-1570, doi: 10.13031/ trans.57.10030.

Weltz, M.A., K. Spaeth, M.H. Taylor, K. Rollins, F. Pierson, L. Jolley, M. Nearing, D. Goodrich, M. Hernandez, S.K. Nouwakpo, and C. Rossi. 2014b. Cheatgrass invasion and woody species encroachment in the great basin: Benefits of conservation. Journal of Soil and Water Conservation 69(2):39A44A. https://doi.org/10.2489/jswc.69.2.39A.

Wischmeier,W., and D. Smith. 1965. Prediction RainfallErosion Losses from Cropland East of the Rocky Mountains: A Guide for Selection of Practices for Soil and Water Conservation. Agriculture Handbook No. 282. Washington, DC: USDA

Wischmeier, W.H., and D.D. Smith. 1978 Predicting Rainfall Erosion Losses: A Guide to Conservation Planning. USDA Handbook No. 537. Washington, DC: USDA

Woodruff, N.P., and F. Siddoway. 1965. A Wind Erosion Equation 1. Soil Science Society of America Journal 29:602-608.

Zhang,Y., M. Hernandez, E. Anson, M.A. Nearing, H Wei, H.,J.J.Stone, and R.Heilman. 2012. Modeling climate change effects on runoff and soil erosion in southeastern Arizona rangelands and implications for mitigation with conservation practices. Journal Soil and Water Conservation 67(5):390405. https://doi.org/10.2489/jswc.67.5.390. 